\title{
Reliability-Based Design of Solid and Nail-jointed I-Section of Nigerian-Grown African Birch (Anogeissus leiocarpus) Timber Column
}

\author{
${ }^{* 1}$ WILSON, UN; ${ }^{2}$ ADEDEJI, AA; ${ }^{1}$ ORIOLA, FOP; ${ }^{3}$ ALOMAJA, JA; ${ }^{1}$ SANI, JE \\ ${ }^{* 1}$ Department of Civil Engineering, Nigerian Defence Academy Kaduna, Nigeria. \\ ${ }^{2}$ Department of Civil Engineering, University of Ilorin, Ilorin. Nigeria. \\ ${ }^{3}$ Department of Civil Engineering, Adeleke University Ede, Nigeria. \\ *Corresponding Author Email: unwilson@nda.edu.ng
}

\begin{abstract}
The Nigerian-grown African birch timber was used to assemble I- section specimens which were tested in the laboratory for their compressive strengths. Solid square sections of the same specie were similarly tested for an apt comparison of results. A structural reliability analysis was carried out for these two sections to ascertain their performance as structural timber columns using statistical parameters that were determined for the deterministic design of the timber column. A FORTRAN-based program was also developed and used for the reliability analysis of the Nigerian-grown African birch columns designed to ascertain their level of safety using First-Order Reliability Method (FORM). The 'I'section was found unsafe to bear the design load unlike its corresponding solid section. An identified I- section of ( $100 \mathrm{x}$ $400 \mathrm{~mm}$ ) was found adequate (with $\mathrm{P}_{\mathrm{f}}=1.22 \times 10^{-02}$ ) whose compressive resistance corresponds to $(200 \times 100 \mathrm{~mm})$ of the solid section (with $\mathrm{P}_{\mathrm{f}}=7.76 \times 10^{-02}$ ) which is practically half the dimension of the I-section. This shows that the solid section has a capacity twice that of the 'I'- section of equal dimensions. However, considering the minimum dimension of the of the two sections capable of supporting the design load, the 'I'- section is more economical than the solid section since it offers a less effective area of $11,200 \mathrm{~mm}^{2}$ compared to the solid section with an effective area of $20,000 \mathrm{~mm}^{2}$. The 'I'-section also showed a higher capacity to bear the Euler load with greater lengths than the solid section because of its greater radius of gyration and rigidity value and would be rather preferable for long columns than the solid section. Considering the limited availability of larger dimensions of solid sections, the built-up I- section would be more relevant where large sized sections are required.
\end{abstract}

\section{DOI:https://dx.doi.org/10.4314/jasem.v23i7.22}

Copyright: Copyright (C) 2019 Wilson et al. This is an open access article distributed under the Creative Commons Attribution License (CCL), which permits unrestricted use, distribution, and reproduction in any medium, provided the original work is properly cited.

Dates: Received: 18 May 2019; Revised: 21 June 2019; Accepted 11 July 2019

Keywords: Solid section, Compressive capacity, Built-up sections, Reliability, Probability of failure $\left(\mathrm{P}_{\mathrm{f}}\right)$.

Steels produced for structural purposes in steel rolling mills have standard sections with their identified properties such as unit weight, area of cross-sections, moment of inertia and radii of gyration for specified uses. For certain structural steel works which involve deep beams and large-sized columns, sections other than the standard ones are needed and this would require fabrication since they are not available in the steel rolling mill. These fabricated sections are generally referred to as built-up sections. This is usually achieved by assembling flat steel plates by use of welds, rivets and bolts into different geometric configurations for the desired structural element. Timber, being a natural construction material has its peculiar limitations when used for structural purposes. First, being anisotropic in nature, it can to a little extent have its strength properties varied or improved. Second, its natural growth size limits the available solid sections especially with the existential problem of increase in indiscriminate felling of forest trees whereby timbers are not allowed to attain their optimal trunk size before felling. It therefore means that there could be reasons for which built-up sections would be required in timber akin to steel structures and this is possibly the best way of providing larger sections of timber. Analogous to the built-up sections in structural steel, built-up sections for timbers can also be achieved by joining different timbers in any varied choice of geometry with the intent of primarily increasing the section of the timber beyond the naturally existing one and consequently its capacity. Laminated sections also exist which can be manufactured by joining several thin layers of timber parallel to each other to a certain thickness to form a complete section. The laminated section which is one of the available built-up sections, can be fabricated using strong glues such that the entire section acts as a unit and any failure that must occur, should be only traceable to the timber and not the adhesive. Sometimes in the built-up sections, pins or nails may be used. This must be done in such a way that any failure must not be traceable to joint locations. The fact that possible failures must not be traceable to joints is necessary either for the case of glues or nails because, 
the timber strength is of utmost importance to the engineer since the structural element is not designed as a composite material so to speak in that the materials used are same. Usually, the individual members joined together to make up the laminated or built-up sections are carefully selected such that they are of excellent properties and truly representative of the ideal condition of the timber. This is done for the purpose of having a resultant section with equally excellent properties usually relative to the corresponding solid section. By doing these, timber as a material is to some extent made to become semi-artificial in that it can be fabricated into different geometrical configurations like I-sections, box-sections, T-sections, rectangular sections, square sections. Also, the size of the sections can be increased beyond the naturally available sizes of the timber or beyond the standard preferred sizes in which they are converted to. Consequently, the load carrying capacity (that is moment capacity for beams, compressive and buckling resistance for columns) of the timber would be increased thereby maximize the timber as a construction material. In this work, a solid African birch column was compared to an I-section of corresponding dimension to evaluate the performance (that is from the reliability analysis) as well as their capacity. Wilson et al (2018) in a study on a reliabilitybased design of a solid African birch timber column showed that the Nigerian-grown African birch is a satisfactory structural material for use as solid timber columns at a depth and breadth of $150 \mathrm{~mm}$, effective length of $3600 \mathrm{~mm}$ and an axial load of $260 \mathrm{kN}$; with a probability of failure $8.85 \times 10^{-3}$. It was discovered that a column of similar effective length can at a depth of $400 \mathrm{~mm}$, breadth of $200 \mathrm{~mm}$ support an axial load of $1000 \mathrm{kN}$ with a probability of failure of $4.85 \times 10^{-2}$. The reliability by failure rate method was also considered and it was observed that the Nigeriangrown African birch has a higher failure rate at an interval of 10 years over a 100 years expected lifespan in bending when compared to compression and this can be attributed to their respective basic compressive and bending strength values. Aguwa and Sadiku (2011) from a reliability studies showed that the Nigerian Ekki (Lophira alata) timber is a satisfactory structural material for timber bridge beams at depth of $400 \mathrm{~mm}$, breadth of $150 \mathrm{~mm}$ and span of 5000 to 7000 $\mathrm{mm}$ under the ultimate limit state of loading. Its probability of failure in flexure under the specified operating conditions is $1.1 \times 10^{-7}$, that is, one in ten million. If an optimization was carried out, a more economical section and span would have been found. Aguwa (2012) showed from a reliability studies that the Nigerian grown Apa (Afzelia bipindensis) timber is a satisfactory structural timber for bridge beams at depth of $400 \mathrm{~mm}$, breadth of $150 \mathrm{~mm}$ and span of $5000 \mathrm{~mm}$ under the Ultimate Limit State of Loading.
The probabilities of failure of the Nigerian Apa timber bridge beam in flexure and deflection are $2.062 \times 10^{-3}$ and $2.673 \times 10^{-14}$ respectively, under the design conditions.

\section{MATERIALS AND METHODS}

A total of twenty specimens of I sections of African birch (Anogeissus leiocarpus) timber were prepared for testing by being sawn into specified sizes of $45 \mathrm{x}$ $85 \times 100 \mathrm{~mm}$ for the compressive strength test. The specimens were systematically mounted on the machine, clamped and gradually loaded as readings were automatically taken by the machine. After taking the compressive strength of the specimens, their respective moisture contents were taken since the moisture content is a very consequential property upon which the strength of the timber is dependent.

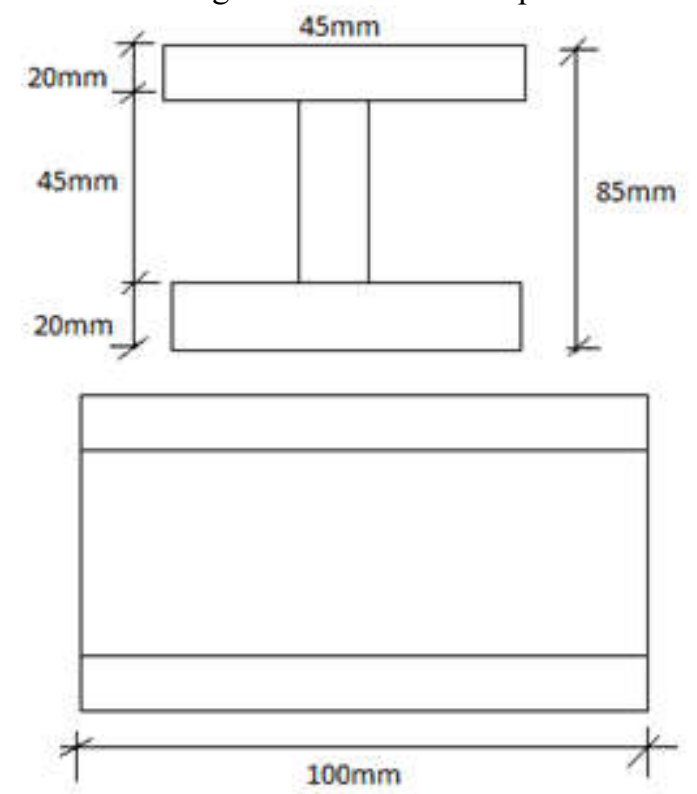

Fig 2Sketch of I-Section Test Specimen for Compression Test

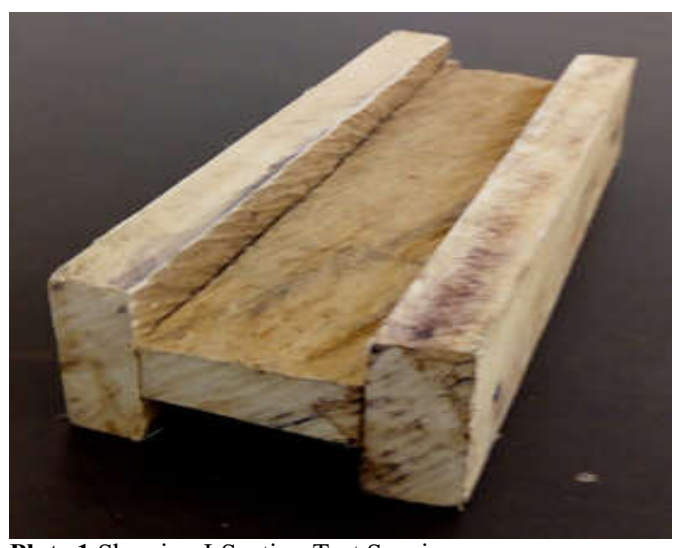

Plate 1 Showing I-Section Test Specimen

The limit state or performance function in compression as given by (Nowak and Collins 2000) $g(x)=f_{p \text { par }}-f_{\text {a par }}$. 
Where: $f_{p \text { par }}=$ Permissible stress parallel to grain; $f_{a \text { par }}=$ Actual stress parallel to grain

From the basic stress gotten for the solid timber, the limit state function can be written as

$g(x)=16.25-\frac{N}{b h}$

Wilson et al., (2018)

To consider the reliability of the timber with an interest in considering the length in response to the performance, the limit state function formulated from the Euler load formula and can be given by

$g(x)=16.25-\frac{9.88 E r^{2}}{l^{2}}$

Where: $E=$ Youngs' Modulus of elasticity; $r=$ radius of gyration; $1=$ length of the column

Wilson et al., (2018)

From the basic stress gotten for the I-section timber, the limit state function can be written as

$g(x)=9.23-\frac{N}{b h}$

To consider the reliability of the I-section timber column with an interest in considering the length in response to the performance, the limit state function formulated from the Euler load formula and can be given by

$$
g(x)=9.23-\frac{9.88 E r^{2}}{l^{2}}
$$

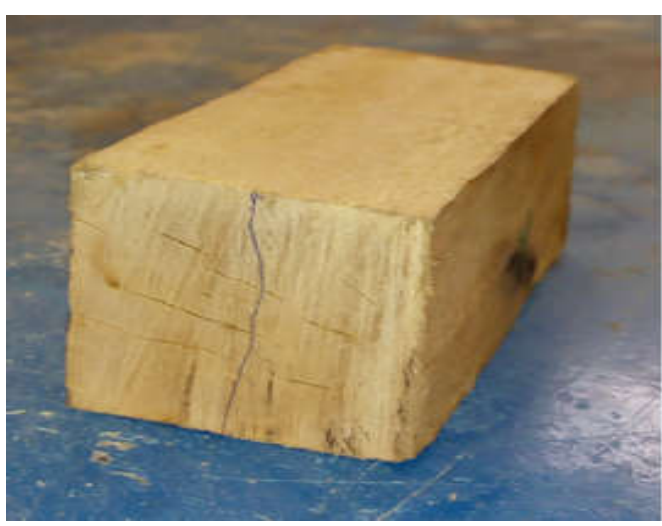

Plate 2 Solid Section Test Specimen

\begin{tabular}{|c|c|c|c|c|}
\hline Parameter & Distribution & Mean & Standard deviation & $\mathrm{COV}$ \\
\hline Load (N) & $\mathrm{Log}$ & 250 & 35 & 0.14 \\
\hline Breadth(mm) & Normal & 150 & 9 & 0.06 \\
\hline $\operatorname{Depth}(\mathrm{mm})$ & Normal & 150 & 9 & 0.06 \\
\hline Young's Modulus $\left(\mathrm{N} / \mathrm{mm}^{2}\right)$ & Log Normal & 10.500 & 315 & 0.03 \\
\hline Length (mn) & Nornal & 3600 & 432 & 0.12 \\
\hline Radius of zyration (mun) & Normal & 28.57 & 1.44 & 0.05 \\
\hline
\end{tabular}

Wilson et al., (2018)

Table 2. Design Parameters for the Nigeria- grown African birch

Timber Specie Span(mm) Depth(mm)Breadth (mm) Design Load kN

\begin{tabular}{lllll}
\hline Africa Birch & 3600 & 150 & 150 & 260
\end{tabular}

Wilson et al., (2018)

Table 3 Probability distribution and Statistical parameters for the basic variables for I- Section of Timber.

\begin{tabular}{llllll}
\hline S/N & Parameters & Distribution & Mean & Standard deviation & COV \\
1. & Load $(\mathrm{N})$ & Log & 250 & 35 & 0.14 \\
2. & Breadth $(\mathrm{mm})$ & Normal & 150 & 9 & 0.06 \\
3. & Depth $(\mathrm{mm})$ & Normal & 150 & 9 & 0.06 \\
4. & Young's Modulus $\left(\mathrm{N} / \mathrm{mm}^{2}\right)$ & Log Normal & 10,500 & 315 & 0.03 \\
5. & Length $(\mathrm{mm})$ & Normal & 3600 & 432 & 0.12 \\
6. & Radius of gyration $(\mathrm{mm})$ & Normal & 37.12 & 1.86 & 0.05 \\
\hline
\end{tabular}

Analysis of the column: When the column is considered as short, the axial stress is given by the expression

$\sigma=\frac{P}{A}$

Where $\mathrm{P}$ is the load supported by the cross sectional area $\mathrm{A}$. For long columns, the equation given by Euler is

$\mathrm{P}=\frac{\pi^{2} E I}{L^{2}}$

Where $\mathrm{P}$ is the maximum critical load, $\mathrm{E}$ is the elastic modulus and I the moment of Inertia.
The radius of gyration is given by

$r=\sqrt{\frac{I}{A}}$

The corresponding Euler stress experienced by the slender column can consequently be expressed by the expression (Jimoh, 2005)

$\sigma=\frac{\pi^{2} E}{(L / r)^{2}}$

\section{RESULTS AND DISCUSSION}

Results of Reliability Using a Fortran-Based First Order Reliability Method Program for Both the Solid and I-Section Column. When putting to consideration the design dimension- $(150 \times 150 \mathrm{~mm})$ for the I and 
solid section subjected to similar load ranging from $75 \mathrm{kN}$ to $350 \mathrm{kN}$, it was observed that the solid section possesses a higher safety index than the 'I'- section by more than 3.0 and from a load of $200 \mathrm{kN}$ and above, the I- section begins to tend to failure. This is indicated by the probability of failure gotten from the analysisat $200 \mathrm{kN}$, its $\mathrm{P}_{\mathrm{f}}=0.386$. At $250 \mathrm{kN}$, a $\mathrm{P}_{\mathrm{f}}$ value of 0.860 ; at $300 \mathrm{kN}$ the probability of failure is 0.986 and at $350 \mathrm{kN}$, the probability of failure is 0.999 . This is possibly traceable to the cross sectional area provided. The I-section can safely support a maximum load of $150 \mathrm{kN}$ at a probability of failure of 0.02 . The solid section can safely support as much as $300 \mathrm{kN}$, which is actually twice as much as the I-section of similar cross-section can support at a probability of failure of 0.103 .

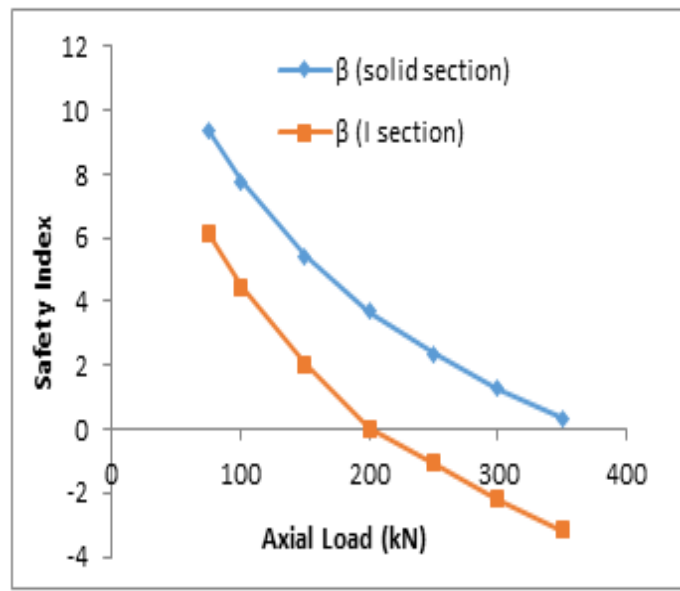

Fig 3 Safety Index- Axial Load Relationship for the Design Section $(150 \times 150 \mathrm{~mm})$

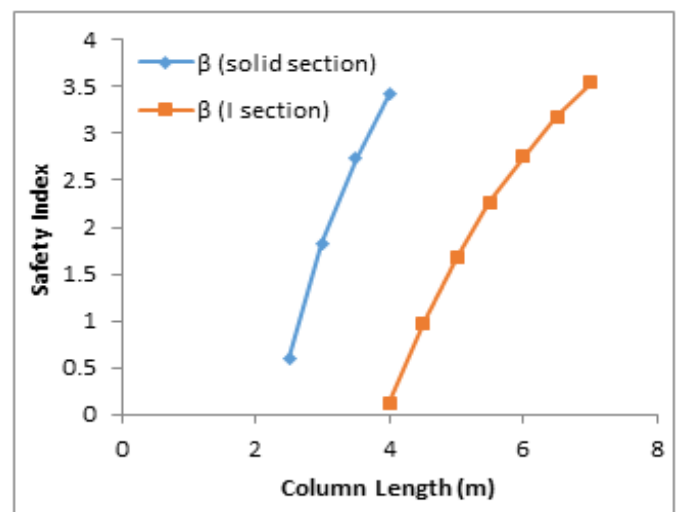

Fig 3 Safety Index- Column Length Relationships for the Design Section

Figure 3 shows the relationship between the safety index and column length under the Euler loading condition for the solid and I-section. The graph shows a very safe maximum column height of up to $4.0 \mathrm{~m}$ for the solid section. The I-section is capable of sustaining its Euler load to a safe maximum length of $7.0 \mathrm{~m}$ with a probability of failure of $1.97 \times 10^{-4}$.It can be deduced that the 'I'-section depicts a higher safety index at longer lengths than the solid section. This invariably translates to the suitability of the I-section for longer columns than the solid column. This is apparently owing to its greater radius of gyration than the solid section.

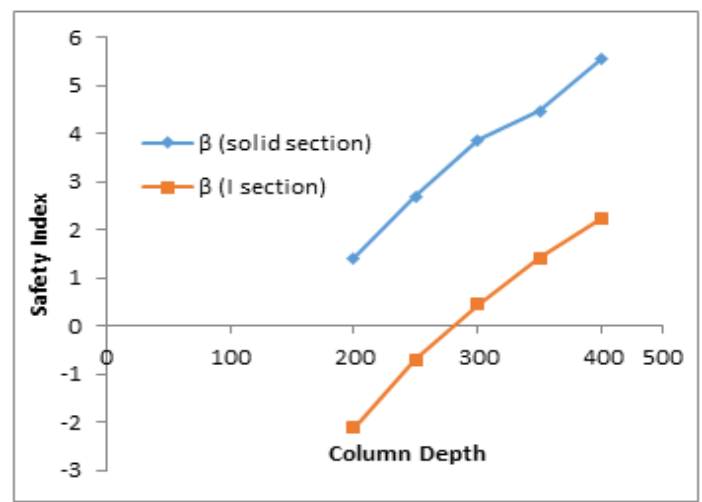

Fig 4 Safety Index-Column Depth Relationship at 100mm breadth

Figure 4 shows the relationship of the safety index with varied column depths for a constant breadth of $100 \mathrm{~mm}$ to support the design load of $260 \mathrm{kN}$.The safety index-column depth relation shown in the figure 4 above depicts the performance of the two different section geometries: the solid and I-section under the design axial load of $260 \mathrm{kN}$ and a constant breadth of $100 \mathrm{~mm}$. It can be deduced that the I-section can safely support this load with a minimum depth of $400 \mathrm{~mm}$ (that is a $100 \times 400 \mathrm{~mm}$ section) at a probability of failure of $1.22 \times 10^{-2}$. It is noteworthy that the I-section can with a depth of $350 \mathrm{~mm}$ perform for serviceability purpose since it has a safety index of 1.149 and a corresponding probability of failure value of $7.8 \times 10^{-}$ ${ }^{2}$ but, the negative safety indices show unsafe margins for the depth.

The solid section can support the design load with a minimum depth of $200 \mathrm{~mm}$ (that is a $100 \times 200 \mathrm{~mm}$ section), actually half the size of the I-section at a probability of failure of $7.76 \times 10^{-2}$. Taking into cognizance a design load of $500 \mathrm{kN}$ with a constant column breadth of $150 \mathrm{~mm}$, it can be observed that the I-section would not safely bear this load even with a depth of $400 \mathrm{~mm}$ (that is, a $150 \times 400 \mathrm{~mm}$ section). This is because it has a safety index value less than 1.0 which is indicative of an unsafe and inadequate section (with $P_{f}=0.247$ ) both at serviceability and ultimate limit state except there is an increment in the depth. The solid section can on the other hand support this design load with a minimum depth of $300 \mathrm{~mm}$ (that is, a $150 \times 300 \mathrm{~mm}$ section) or less at a probability of failure of $8.85 \times 10^{-2}$. 


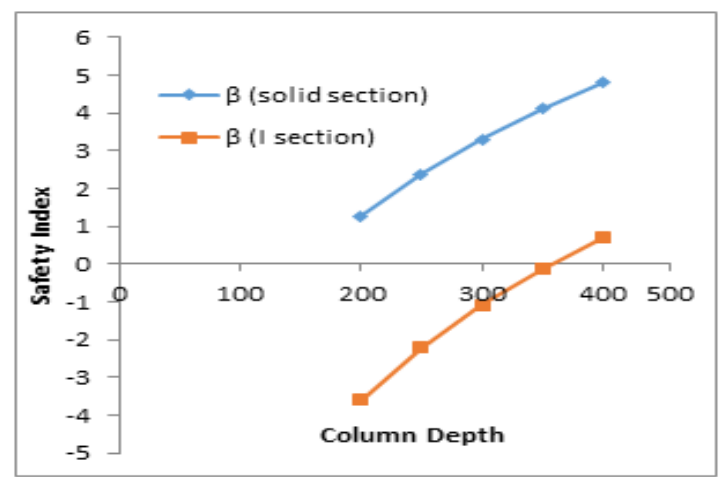

Fig 5 Safety Index-Column Depth Relationship at 150mm breadth

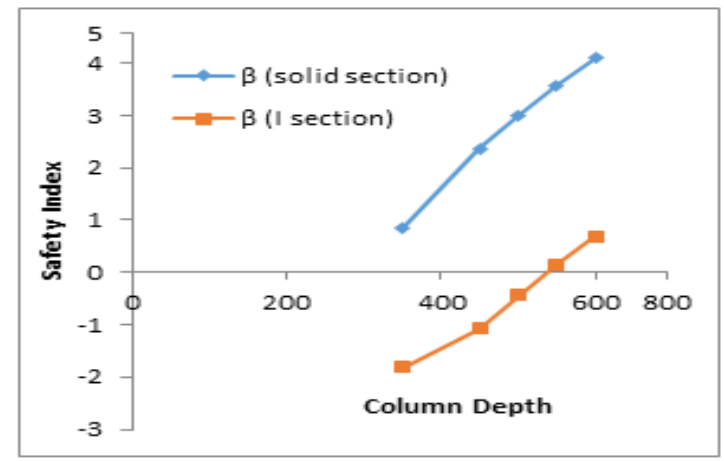

Fig 6 Safety Index-Column Depth Relationship at 200mm breadth

Considering the whole scenario when a load of $1000 \mathrm{kN}$ is supported by both sections of breadth $200 \mathrm{~mm}$ and increasing values of the depths, it can be shown and established that there is an increasing departure between the compressive capacity of the solid and I section of similar dimension. The I section was observed to still be inadequate even with its maximum section of $(200 \times 600 \mathrm{~mm})$ with a probability of failure of 0.247 .

Conclusion: From a panoramic consideration of the reliability-based design carried out for the solid and Isection column of the African birch timber, the following deductions can be made. (1) In view of the design section $(150 \times 150 \mathrm{~mm})$ provided, the solid section possesses a compressive capacity that is twice as much as that of the I-section. The I-section was therefore not found adequate and suitable for the design load considering the safety index and probability of failure gotten from the reliability analysis. (2) An identified minimum depth of $400 \mathrm{~mm}$ (that is $100 \times 400 \mathrm{~mm}$ section) was found adequate since the provided dimension $(150 \times 150 \mathrm{~mm})$ for the
I-section is unsafe to bear the design load. This capacity was found to correspond to a minimum depth of $200 \mathrm{~mm}$ (that is $200 \times 100 \mathrm{~mm}$ section) of the solid section which is practically half the dimension of the I-section. This further accentuates the fact that the solid section has a capacity twice that of the I- section of equal dimension. However, if the minimum dimension of the of the two sections capable of supporting the design load is of interest, the I- section is considered more economical than the solid section since it offers a less effective area of $11,200 \mathrm{~mm}^{2}$ compared to the solid section with an effective area of $20,000 \mathrm{~mm}^{2}$. (3). The I-section has shown a higher capacity to bear the Euler load with greater lengths than the solid section because of its greater radius of gyration and rigidity value and would be rather considered preferable for long columns than the solid section. (4) When considering the limited availability of large dimensions of solid sections, the built-up Isection would be more relevant where large sized sections are required.

\section{REFERENCES}

Aguwa, J.I. and Sadiku, S (2011). Reliability studies on Nigerian Ekki (Lophira alata) Timber as Bridge Beam in Bending under the Ultimate limit state of loading. J. Civil Engineer. Construct. Technol. (11), 253-259,

Aguwa, J.I. (2012). Reliability Assessment of Nigerian Apa (Afzelia bipindensis) Timber Bridge Beam Subjected to Bending and Deflection under the Ultimate limit state of loading. Inter. $J$. Engineer. Technol. 2. (6). 1076-1088,

Jimoh, AA (2005). Ultimate Design Strength of Axially Loaded 'Ayin' (Anogeissus leiocarpus) Timber Columns. J. Appl. Sci.Technol.10. 1 \& 2: 029-034.

Nowak AS, Collins KR (2000).Reliability of Structures, McGraw-Hill Companies, USA.pp. 337.

Wilson U.N., Adedeji A.A., Sani J.E., Alomaja J.A. (2018). A Reliability-Based Design of NigerianGrown African Birch (Anogeissus leiocarpus) timber on its Compressive Strength. Epistemics in Sci. Engineer. Technol. 8, (1). 2018, 593-598. 